\title{
Towards Genuine Universalism within Contemporary Development Policy
}

\author{
Andrew M. Fischer
}

Abstract It is very difficult to know the impact of the MDGs on poverty reduction. On the one hand, poverty measurements are ambiguous, arbitrary and contested, even in the best of cases such as China and India. On the other hand, the mechanisms by which MDGs might have effected poverty reduction are not at all clear, particularly in light of the major global structural processes that condition the impact of aid flows and development more generally. Moreover, the emphasis in the MDGs on absolute measures and the implicit bias towards targeting quite possibly undermine poverty reduction in many contexts. Hence, this article argues that the MDGs should be replaced by a re-politicisation of the mainstream development agenda, together with a genuine revival of emphasis on universalistic modes of social policy as viable means of dealing simultaneously with poverty and inequality.

\begin{abstract}
1 Introduction
Despite the façade of precise estimates, we do not really know what has been happening to global poverty all things considered, particularly when measured against rising costs for education and healthcare, which are mostly not factored into poverty measures, for technical reasons. However, the mechanisms by which the Millennium Development Goals (MDGs) might have effected poverty reduction are not at all clear. The recent literature on the impact of aid on growth offers little useful insight given that it largely ignores the major global structural processes that condition the impact of aid flows, such as those reflected by global balance of payments asymmetries. Moreover, the emphasis in the MDGs on absolute measures and the implicit bias towards targeting quite possibly undermine poverty reduction in many contexts, particularly if poverty is primarily considered as an outcome of dynamic processes of social stratification and subordination.
\end{abstract}

Serious consideration of the erosion of decent employment and wages and the increasing segmentation of social security systems throughout the developing world is particularly needed if we are to truly embrace a pro-poor agenda, i.e. not one that merely reduces absolute poverty regardless of inequality, but one that actually promotes equitable sharing without double standards.

\section{Measuring poverty reduction}

At the outset, the impact of the MDGs on poverty reduction, here defined as income poverty as per Goal 1 of the MDGs, is very difficult to assess because poverty reduction itself is very difficult to measure. The international estimates provided by the World Bank are highly contested, even though they are the main data relied upon by the leading international organisations spearheading the promotion of the MDGs. This received much attention through the debate between Reddy and Pogge (2002a,b) and Ravallion (2002), which was furthered by Wade (2004) among others. Much of the contention relates to the way that the purchasing-power-parity (PPP) poverty line had been calculated and standardised. Together with other considerations, Reddy and Pogge (2002a) conclude that the World Bank's estimates of the magnitude, distribution or trend of global income poverty are neither meaningful nor reliable. 
This is just one example of the contention underlying the façade of precision in the field of poverty studies. Given the wide variety of fairly arbitrary assumptions and choices that are required in order to first choose a line and then to apply this line to presumably accurate survey data in ways that are broadly consistent, accurate and comparable across time and regions, it is no surprise nor exaggeration that poverty estimates themselves are quite arbitrary, even before considering World Bank PPP adjustments. Saith (2005) eloquently synthesises the perils, although practitioners of poverty measurement have acknowledged the pitfalls for decades. Indeed, in the opening pages of Poverty Comparisons, Ravallion (1992: 2-3) admits that poverty lines are arbitrary, albeit he argues that even arbitrarily chosen lines nonetheless allow for comparison and evaluation so long as they are accurately adjusted over time.

However, the issue of adjustment leads to the classic quandary that we simply do not know whether poverty trends over time reflect actual changes or else errors of adjustment. The quandary is all the more problematic given that the incomes of populations in poor countries tend to be densely clustered around a typical line, resulting in an extreme sensitivity of poverty estimates to small adjustments to the line, whether or not these are accurate. For example, Székely et al. (2000) apply sensitivity analysis to household survey data from 17 Latin American countries in the 1990s. By varying the poverty line parameters within reasonable boundaries, they estimated poverty rates as lying anywhere from 12.7 per cent to 65.8 per cent of the total population. Moreover, the ranking of countries with respect to poverty rates was also highly sensitive to their exercise. Hussain (2003) demonstrates a similar point with respect to urban poverty in China regarding both sensitivity and rank orderings across Chinese provinces. Helwege and Birch (2007: 6) note that, ironically, 'the institutions that generate poverty data are well aware of how methodological choices affect poverty estimates. They simply have not established standardised approaches to measuring poverty'.

Moreover, poverty trends can differ depending on where or how a line is drawn. For instance, poverty was decreasing in China from 1998 to 2000 according to the unreasonably-low official poverty line (i.e. the one often cited in World Bank publications in the early 2000s), but it was rising according to the more reasonable absolute poverty line calculated by the Chinese National Bureau of Statistics (Hussain 2001, cited in Fischer 2005: 96-9). Similarly, based on their efforts to correct inconsistencies in Indian survey data from 1999-2000, Himanshu and Sen (2004) conclude that there had been little poverty reduction in India in the 1990s, contrary to the dominant consensus. Deaton and Kozel (2005: 117) contend that such claims are 'frankly political' and that there is good evidence that poverty fell. However, further findings presented by Himanshu (2007), based on new data from 2004-05, confirmed his earlier results for the 1990s, alongside other studies that repeatedly found that calorie deprivation had actually increased in India in the 1990s (e.g. see Meenakshi and Vishwanathan 2003). Likewise, in their assessment of alternative poverty estimates from the World Bank and the United Nations for Latin America, Helwege and Birch (2007) advise caution in interpreting trends from any of these data.

Our ability to track poverty trends over time is critically based on our presumption that we can accurately measure all of the changing cost factors faced by poor households together with their changing patterns of livelihood and consumption, in contexts of often rapid structural change. Notably, the World Bank recently revised upwards its estimates for global PPP poverty rates, including an upward adjustment of about 40 per cent for China. This was based on new and improved cost of living data from 2005, which revealed a substantially higher cost of living for the poor in developing countries than was previously estimated from older data. However, Chen and Ravallion (2008) stress that, although poorer than previously thought, the world was no less successful in poverty reduction. They reach this conclusion simply by deflating the new PPP poverty lines by the official consumer price indices of each country back to 1981 (Chen and Ravallion 2008: 14-15). In other words, the fact that the resultant trends were the same as before is merely an artefact of their assumption that the source of error was the same in 1981 as it was in 2005. In so doing, they completely sidestep the question of whether the poor faced greater cost of living increases than suggested by the general 
consumer prices indices, which is quite possible given the notable increases in inequality in many countries over the same period. ${ }^{1}$ Thus, while Chen and Ravallion provide a politically convenient narrative, many intractable problems remain lost in past surveys.

Arguably, the fundamental Achilles heel of the income poverty approach is that education and health costs are mostly not included in the calculation of poverty lines. The exclusion is for technical reasons, given that they constitute large and highly irregular expenditure items across households and across time. However, they are included in the expenditures of surveyed households. This renders the comparison of poverty rates very difficult across households, let alone across regions with different provisioning systems or else across time when the costing and supply of education or healthcare changes.

Increasing costs of education or healthcare, or else increasing school enrolments in schools that charge fees, would be invisible to most conventional poverty measures even though they effectively raise the poverty line for a large proportion of households, leading to an important source of underestimation of poverty rates in such contexts. This weakness is recognised in some of the literature, but it is also generally sidestepped in the same literature (e.g. see Ravallion 1992: 12, 28).

The innovative work by van Doorslaer et al. (2005) is one exception in this regard. Merely by deducting catastrophic out-of-pocket payments for healthcare from the expenditures of households surveyed in 11 low- and middleincome countries in Asia (most surveys taken around 2000), they show that poverty rates across Asia increased from 19.3 per cent to 22 per cent, or an increase of 78 million people. Notably, this does not take into account the repressed expenditure of poor people who would have otherwise spent more on necessary healthcare were it not for lack of funds, which is a problem that the authors consider but cannot measure.

As insightful as this work is, it is nonetheless based on insights from single surveys taken at one particular point in time. The results offer no indication on how these considerations might alter our perception of trends over time, particularly in cases where education and healthcare costs have increased substantially. For instance, falling income poverty rates in China since the beginning of the reform period do not factor into consideration the parallel shift from very cheap to very expensive healthcare. More specifically, while general consumer prices in China remained more or less unchanged between 1997 and 2004, tuition fees and healthcare services were extremely inflationary, especially in some of the poorest western provinces such as Qinghai, where prices for healthcare services more than quadrupled (see Fischer 2005: 48). By ignoring such dramatically changing price structures (as do Ghen and Ravallion 2008), we simply do not know to what degree the appearance of improving poverty rates merely represents increasing relative prices for these essential services not included in the poverty line.

It is in this sense that the exclusive focus on conventional absolute income poverty measures in Goal 1 of the MDGs can be said to be biased against universalistic modes of social policy. A movement towards free education or healthcare financed through progressive taxation would not necessarily appear as decreasing income poverty even though it would lower the effective poverty line for households previously paying fees. Similarly, it is difficult to calibrate poverty rates in any meaningful way across countries with very different provisioning systems, such as between Cuba with its free healthcare and education, and Vietnam, which had the greatest reliance on outof-pocket payments among the Asian cases studied by van Doorslaer et al. (2005). Indeed, much of the appearance of rising incomes in the latter case might actually signify deteriorating social wealth.

\section{Global structural processes and aid}

The other side of the question on the poverty impact of the MDG paradigm is that the mechanisms by which MDGs might have effected poverty reduction are simply not clear. Notably, the major episodes that account for a large part of the commonly cited absolute income poverty reduction over the last several decades had little to do with MDGs, for example China in the 1980 s or the financially driven global economic boom of 2002-07. The mechanisms that could continue to drive poverty reduction now that this boom has bust are even less clear and the MDGs provide little guidance. Hope is placed on the aid system. However, the recent literature on the impact of aid on growth and poverty offers little 
useful insight, given that attention is rarely given to the major global structural processes that condition the impact of aid flows and development more generally.

On this last point, as argued in Fischer (2009), there is no sense in discussing whether aid is good or bad for development, or whether more or less aid is required for development, outside of a much broader understanding of the key factors underlying cases of successful development up to the present, namely industrialisation and large sunk investments in urban and other infrastructure. These in turn usually necessitate that developing countries run trade deficits rather than surpluses. In an earlier developmental epoch, aid was understood as enabling poor countries to cover such trade deficits, as best represented by the crucial role of aid in the balance of payments of South Korea well into the $1970 \mathrm{~s}$. The recent exceptionality of China might seem to counter this rule, although this is debatable. In any case, its replication or sustainability is questionable if only because the world economy has probably reached its limits of disequilibria.

The role of aid must be considered in this light because aid will have very different macroeconomic implications depending on whether a receiving country is in current account deficit or surplus. Moreover, even if a country is in deficit, aid would presumably have very different effects on growth depending on whether the deficit is due to productive investment and accumulation, or simply due to terms of trade and other contractionary shocks, or to austerity and structural adjustment programmes (SAPs). Indeed, many of the arguments on aid and growth are rendered trivial by their lack of consideration of these broader structural considerations.

Similarly, it is meaningless to argue that large increases in aid would produce better development (e.g. Sachs 2005) without examining the international mechanisms set in place to deliver aid, which for much of the last three decades have encouraged a haemorrhaging of human, physical and financial resources from poor to rich countries. The same can be said of arguments that aid effectiveness could be improved by improving incentive mechanisms within poor countries (e.g. Easterly 2006), irrespective of the globalised incentive mechanisms that play a strong role in disorienting local incentives. The frivolity of these arguments is best highlighted by the massive US current account deficit, many times the size of the annual aid budget of the Organisation for Economic Cooperation and Development (OECD) countries and largely financed by the developing world.

More pertinent is the fact that, in the midst of a crushing depression in the 1980s and into much of the 1990s, Africa was experiencing net outflows of capital that far exceeded any inflows of aid. Collier (2007: 91-3) discusses this point to some extent but does not place it within the context of the systemic shifts in global economic structures and ideologies that produced these outcomes, with the result that he conflates many symptoms as causes. This is expected given that he broadly positions himself within the hegemonic paradigms and institutions of this period, as do Sachs and Easterly. Indeed, Collier (2007) mostly avoids mention of the 1982 debt crisis and seems to imply that SAPs themselves constituted good economic policy.

Similar obfuscations are committed throughout the cross-country regression literature on aid. Data from two entirely different epochs of development are usually merged together without differentiating the radically different structured settings in which aid might or might not work. Crucial in this regard is the difference between the epoch of developmentalism up to the 1970s, when most Southern countries experienced decent economic performance, versus the current period that started in the early 1980s, after which Southern performance has been much worse outside of East and South Asia and aid flows have become a trickle in comparison to successive waves of capital flows from poor to rich countries. Aid has since been futile in producing any significant degree of net global redistribution.

In the absence of these broader considerations, the MDG agenda has tended to encourage an over-inflated sense of self-importance among international donors about the role that aid can play in driving development. This exaggeration is all the more evident when we consider that probably the majority of aid flows return to their donors, if ever they even leave the shores of their donor, such as in the case of technical assistance, 
consultancies and research funding. ActionAid (2005) has produced some interesting research on the uses and abuses of such 'phantom aid'. Academics should take these issues much more seriously, although perhaps their avoidance derives from fear of biting the hands that feed.

This being said, there are particular moments when the aid industry does play a very pivotal role. These are in times of economic crisis, when developing countries start to face balance of payments problems and potential financial crises. The aid industry is then suddenly possessed with much power, particularly gatekeepers such as the World Bank and the International Monetary Fund (IMF). If guided by an orthodox monetarist agenda, this power can be wielded in punitive destructive ways. This is precisely what happened during the 1982 debt crisis. While the crisis was fundamentally rooted in systemic disequilibria stemming from the breakdown of the Bretton Woods system, the ideological recasting of this crisis as one of irresponsible borrowing by inept and corrupt Southern governments and their host of rent-seeking elites fashioned the justification for policies that shifted most of the burden of adjustment from Northern financial sectors to Southern publics. The recasting also helped to consolidate the rise of what is now called the Washington Consensus. Similar dynamics unfolded with the East Asian financial crisis in 1997-8 and the consolidation of the so-called Post-Washington Consensus. Similar dangers exist today.

\section{Towards re-politicisation and genuine universalism}

In terms of what should replace the MDGs after 2015 , it is important to recall three main criticisms of the MDGs: that they do not pay attention to employment, or inequality, and that they de-politicise development debates. ${ }^{2}$ Of these three, de-politicisation arguably underlies the weakness of the MDGs with respect to employment and inequality.

The reasons for this might seem semantic, but they are not. They are rooted in the fact that policy choices are very political, even though these choices are often couched in seductively technocratic terms. De-politicisation then serves to veil underlying agendas and allows paradigmatic shifts in theory and practice to be hidden behind principles of charity and altruism.
More specifically, the emphasis in the MDGs on absolute measures and the implicit bias towards targeting predisposes the MDG agenda to be coopted by an orthodox approach to development policy.

In this regard, there is much truth to the claim that the MDG agenda has been embedded within the Washington Consensus (including its various 'post' reiterations). It is important to recall that addressing poverty is not particularly antithetical to this consensus. Indeed, the World Bank dedicated its World Development Report specifically to the theme of poverty for the first time in 1990. Lipton et al. (1992) famously called this the 'New Poverty Agenda'. Accordingly, poverty is quite comfortably explained by way of market imperfections. Poverty persists precisely because markets do not function efficiently, causing market failures (i.e. involuntary unemployment or incomes below potential). In times of deregulatory zeal, it is usually argued that these imperfections are largely caused by witless or devious government interventions resulting in countless economic distortions in need of structurally adjusting. Until such adjustments are completed, targeted safety nets should be provided for those who fall through the cracks, provided they are deemed as deserving. Targeting then necessitates accurate poverty measurement. The Post-Washington Consensus basically adds the weakness of marketsupporting institutions (i.e. insecure property rights, poor enforcement of contracts, clientelism, corruption, etc.) to the list of reasons why markets fail without challenging the underlying logic. In other words, talking about poverty does not necessarily signal a shift away from this paradigm. It is often symptomatic of a more conservative agenda that emphasises charity and paternalism, versus more progressive (i.e. redistributive) agendas that emphasise equality and employment. ${ }^{3}$

Similar tendencies exist in the more recent iterations of the poverty agenda. For example, multidimensional conceptions of poverty (which are not at all new, although they have come to be treated as such) can be easily co-opted into a supply-side policy approach, more or less Washington Consensus in nature, i.e. avoid demand management and focus instead on allowing supply to create its own demand, particularly through the operation of efficient 
markets. The recent turn towards conditional cash transfers, wellbeing approaches, and even rights-based approaches also carry this propensity to be co-opted by supply-side approaches.

The point is not that conditionality is inherently wrong, that wellbeing studies have no insights to offer, or that rights are not important. Rather, their adoption within the current paradigm has tended to reinforce a perspective that seeks the causes of poverty in the behaviour of poor people themselves or else in the failings of state intervention beyond a restricted scope of targeted measures focused mainly on activating the poor to help themselves (or at least to get them off welfare). Hence, strategies tend to focus excessively on education or microcredit while neglecting serious consideration of employment generation, particularly employment with decent wages and with terms negotiated by strong labour organisations. Rather, employment generation is vaguely evoked by way of 'flexible labour markets' (how much more flexible can informal labour markets become?). This implies that firms should be free to fire as well as hire and wages should be free to fall as well as to rise (the advice is obviously not meant for tenured university economists).

Keynes' biggest battle in the 1930s was against this conventional wisdom that employment would improve if wages were allowed to fall, which belies the shallowness of claims today that we are all Keynesian now.

The political dimensions of these issues become clearer when placed within the broader context of social policy, i.e. publically provided, funded or regulated services such as education, health and various forms of social security, which serve as the primary policy spaces in which most direct public action on poverty reduction is implemented. As argued by Mkandawire (2005), social policies are fundamentally political exercises given that they are the basis of instituting citizenship rights, redistributing wealth, distributing public goods and articulating the main mechanisms of integration and segregation within societies. Moreover, he highlights the paradox that, historically, poverty alleviation was most successful when it was not necessarily the primary focus of social policies, as opposed to other priorities such as late industrialisation, state consolidation, demand stabilisation, or political cohesion.
The key to this paradox is found within the choice of provisioning modes, i.e. universalism versus targeting. It should be noted that there has been a subtle shift in the implied meaning of universalism in recent years, towards a connotation of universal coverage or access, such as sending all children to school, regardless of how such schooling is provided or financed. While universal coverage is obviously a necessary condition of universalism, it is not a sufficient condition. Rather, universalism is best understood as provisioning through integrated and de-commoditised systems financed indirectly (i.e. not at the time of need) by progressive forms of taxation (i.e. progressive income tax, corporate tax, capital gains tax, etc), rather than through segmented systems financed directly and regressively (i.e. user fees, out-of-pocket payments, etc). While most people can agree on the principle of sending all children to school, it is clear how these other dimensions of universalism are potentially rife with intense political dispute, as currently observed in the battles over healthcare reform in the USA.

As an alternative, targeting has come to be advocated on grounds of efficiency, expediency and even equity. However, as outlined by Mkandawire (2005), targeting can lead to a variety of perverse outcomes. The errors of under-coverage and leakage are the most commonly discussed. Indeed, precision in poverty measurement becomes ever more crucial precisely when social policy regimes shift towards greater selectivity, such as under the social safety net approach of the World Bank. Yet, as Mkandawire notes, poor countries also have among the least administrative capacity to be able to target precisely.

Other perverse outcomes of targeting reside in its political and social implications. Targeting usually entrenches segmentation in provisioning systems, which in turn reinforces social and economic stratification by removing middle classes and their political voice from the services that are supplied to and accessed by the poor. The resulting political economy paradox was best expressed by Richard Titmuss (although often attributed to Amartya Sen), that the targeting of services to the poor usually results in poor services. Insofar as we view poverty as fundamentally rooted in dynamic social processes of stratification, differentiation and 
subordination, these implications are potentially very counterproductive for any long-term strategy of poverty reduction.

Nonetheless, the MDG paradigm is well served by targeting given its focus on absolute Indicators (whether in income, health or education) rather than relative (i.e. inequality) Indicators. For instance, it is relatively easy to raise school enrolments, but much more difficult to raise the quality of schooling, particularly in ways that would significantly alter the employment trajectories of students. This is especially the case when increased enrolments are achieved in stigmatised and lower quality schools designated for poor people within a segmented education system. Indeed, if the quantity and quality of employment and the level of wages faced by the poor are not addressed by poverty reduction strategies, the expectations raised by educational improvements might lead to frustration and alienation in the medium term.

This has precisely been the dilemma of the much-lauded Progresa/Oportunidades conditional cash transfer programme in Mexico. The programme has shown some degree of success in raising consumption levels, certain health outcomes, and school attendance and enrolment rates (Skoufias 2005). These results were obtained with relatively low operational expenses, in large part because the programme was implemented through an already wellestablished network of clinics and schools servicing the targeted rural populations (distinct from the subsidised network servicing the urban middle classes). However, even its proponents, such as Levy (2006), admit that increased coverage was achieved at the cost of lower quality within this overstretched and segmented network. Notably, the programme had no impact on the academic performance of students or on their later local employment prospects. Thus, while it had a positive impact on absolute human development Indicators, it did so at the cost of entrenching the segmentation of provisioning systems and possibly accentuated social stratification as a result.

The obvious rejoinder is that, in the short or even medium term, universalism would be impossible to achieve within the starkly unequal social context of Mexico or most other developing countries. Hence, we must do what we can now.
However, we must also ask why universalistic social policy is not even on the agenda as an explicit long-term Goal. For instance, the World Development Report on services (World Bank 2003) makes no explicit reference to universalism. One of their eight possible sizes (versus one-size-fitsall) is 'central government provisioning', although it is not clear if this implies universalism. In any case, the report argues that this size is only applicable in a context of propoor politics and a homogeneous population that is easy to monitor. In other words, similar to earlier World Bank arguments about South Korea and industrial policy, the report seems to imply that, if you are not Cuba, don't try it at home! Instead, it offers strong implicit endorsement of targeted New Public Management approaches to social policy, promoting choice and client power through various mixtures of decentralisation, private-provisioning, marketisation, user fees and vouchers. Yet, as argued by Dunleavy et al. (2006), even in rich countries with well-developed administrative capacities, the policy complexity introduced by such approaches generally led to a reduction in citizen competence and the tide has since turned in 'leading-edge' countries. More importantly, insofar as we recognise high levels of inequality as problematic, the censor of universalistic social policy from mainstream agendas implies abandoning at the outset some of our most powerful policy tools to date for dealing with inequality.

\section{Conclusion}

The embedding of the MDG agenda into a Washington Consensus paradigm is not simply a matter of one-size-fits-all versus context specificity. Rather, there are some broad general lessons that we can draw from the past. These include universalistic social policies alongside other strategies such as strong state-guided industrial policy and large sunk investments in physical and social infrastructure. Indeed, Mehrotra (2000) points out that in ten cases of 'high human development achievers' (relative to what we would expect from per capita GDP), all practised various combinations of universalistic social policies. Much earlier, Gerschenkron (1962) pointed out that European late industrialisers introduced universalistic social policies before or simultaneous to the initiation of strong industrial catch-up strategies, much earlier than would have been predicted by the experience of more advanced industrial 
countries. In other words, well-established lessons have long been there for us to heed. We do not need to 'discover' new ones. Rather, we need to redefine the agenda now so as to make adopting these lessons easier for the poorest of countries.

Hence, the challenge of the MDGs does not lie in measuring their impact on poverty reduction, but in seriously re-engaging with development debates about how to create genuinely redistributive structures and institutions at national and global levels. These are political challenges given that they cannot be resolved through technocratic solutions, but require choices to be made about the types of societies we wish to inhabit and how we wish to treat each other within and across these societies. These choices are being made in any case under the de-politicising guise of the MDGs, which reinforce tendencies towards targeting and segmentation in the name of urgency and expediency. These choices need to be repoliticised, ideally within the domestic sphere of developing countries themselves as a means to break out of the TINA hangover (i.e. 'There Is No Alternative') and to replace it with principles of national self-determination. Such re-

politicisation needs to be backed up by a genuine revival, in research and in practice, of universalistic social policies as viable options for dealing simultaneously with poverty and

\section{Notes}

* This article is dedicated to the memory of the late Professor Peter Townsend, who was a most formidable examiner but always an immense source of inspiration.

1 See Günther and Grimm (2007) for a discussion of this point in the case of Burkina Faso.

\section{References}

ActionAid International (2005) Real Aid: An Agenda for Making Aid Work, Johannesburg: ActionAid International

Chen, Shaohua and Ravallion, Martin (2008) The Developing World is Poorer Than We Thought, But No Less Successful in the Fight Against Poverty, Policy Research Working Paper 4703, Washington DC: World Bank Development Research Group

Collier, Paul (2007) The Bottom Billion: Why the Poorest Countries are Failing and What Can Be Done About It, Oxford: Oxford University Press inequality, if only because real political deliberation is very difficult to cultivate within a context of starkly unequal and segregated societies.

We should not fool ourselves into thinking à la Martin Wolf that we are Keynesian simply because we support aid or expansionary spending. More fundamentally, we need to address the erosion of decent employment and wages and the increasing segmentation of social security systems throughout the developing world if we are to truly embrace a pro-poor agenda, i.e. not one that merely reduces absolute poverty regardless of inequality (as per the World Bank definition), but one that actually promotes equitable sharing without double standards. This has been a struggle in both North and South alike, although it is important to recognise the degree of hypocrisy that pervades the global system. The current economic crisis has made it ever more evident that rich countries allow themselves an array of macroeconomic and social policies that the leading international financial institutions have banished from the range of permissible options that poor countries can choose from. Hence, perhaps the guiding dictum for the next incarnation of the MDGs should not be 'Make Poverty History (Part Two)' but rather, 'Do unto others as you would have them do unto you'.

2 For elaboration on these three and many other critiques, see Saith (2006).

3 See Marc Wuyts (2002) for a powerful argument along these lines.

Deaton, Angus and Kozel, Valerie (2005) 'Data and Dogma: The Great Indian Poverty Debate', The World Bank Research Observer 20.2: 177-99

Dunleavy, Patrick; Margetts, Helen; Bastow, Simon and Tinkler, Jane (2006) 'New Public Management is Dead - Long Live Digital-Era Governance', Journal of Public Administration Research and Theory 16.3: 467-94

Easterly, William (2006) The White Man's Burden: Why the West's Efforts to Aid the Rest Have Done So Much Ill and So Little Good, New York: Penguin 
Fischer, Andrew M. (2009) 'Putting Aid in its Place: Insights from Early Structuralists on Aid and Balance of Payments and Lessons for Contemporary Aid Debates', Journal of International Development 21: 856-67

Fischer, Andrew M. (2005) State Growth and Social Exclusion in Tibet: Challenges of Recent Economic Growth, Copenhagen: Nordic Institute of Asian Studies Press

Gerschenkron, Alexander (1962) Economic Backwardness in Historical Perspective, Cambridge: Harvard University Press

Günther, Isabel and Grimm, Michael (2007) 'Measuring Pro-poor Growth when Relative Prices Shift', Journal of Development Economics 82: 245-56

Helwege, Ann and Birch, Melissa B.L. (2007) 'Declining Poverty in Latin America? A Critical Analysis of New Estimates by International Institutions', Global Development and Environment Institute Working Paper 07-02, Boston: Tufts University

Himanshu, K. (2007) 'Recent Trends in Poverty and Inequality: Some Preliminary Results', Economic and Political Weekly 42.6: 497-508

Himanshu, K. and Sen, Abhijit (2004) 'Poverty and Inequality in India - I', Economic and Political Weekly 39.38: 4247-63

Hussain, Athar (2003) Urban Poverty in China: Measurement, Patterns and Policies, Geneva: InFocus Programme on Socio-Economic Security, International Labour Organisation

Hussain, Athar (2001) 'Poverty Profile and Social Security in China', unpublished ADB document, Manila: Asian Development Bank

Levy, Santiago (2006) Progress Against Poverty: Sustaining Mexico's Progresa/Oportunidades Program, Washington DC: Brookings Institution Press

Lipton, Michael; Maxwell, Simon; Edström, Jerker and Hatashima, Hiroyuki (1992) The New Poverty Agenda: An Overview, IDS Discussion Paper, Brighton: IDS

Meenakshi, J.V. and Vishwanathan, Brinda (2003) 'Calorie Deprivation in Rural India: 1983-1999/2000', Economic and Political Weekly 38.3: 369-75

Mehrotra, Santosh (2000) Integrating Economic and Social Policy: Good Practices from High Achieving Countries, Innocenti Working Paper 80, Florence: UNICEF Innocenti Research Centre

Mkandawire, Thandika (2005) Targeting and Universalism in Poverty Reduction, Social Policy and Development Programme Paper 23,
Geneva: United Nations Research Institute for Social Development

Ravallion, Martin (2002) 'How Not to Count the Poor? A reply to Reddy and Pogge', mimeo, www.columbia.edu/ sr793/wbreply.pdf (accessed November 2009)

Ravallion, Martin (1992) Poverty Comparisons: A Guide to Concepts and Methods, LSMS Working Paper 88, Washington DC: World Bank

Reddy, Sanjay G. and Pogge, Thomas W. (2002a) 'How Not to Count the Poor' (version 3.0), mimeo, Barnard College, New York

Reddy, Sanjay G. and Pogge, Thomas W. (2002b) 'How Not to Count the Poor! A Reply to Ravallion', mimeo, 15 August, www.columbia.edu/ sr793/poggereddyreply.pdf (accessed November 2009)

Sachs, Jeffrey D. (2005) The End of Poverty: Economic Possibilities of Our Time, London: Penguin

Saith, Ashwani (2006) 'From Universal Values to Millennium Development Goals: Lost in Translation', Development and Change 37.6: 1167-99

Saith, Ashwani (2005) 'Poverty Lines Versus the Poor: Method Versus Meaning', Economic and Political Weekly 40.43: 4601-10

Skoufias, Emmanuel (2005) PROGRESA and its Impacts on the Welfare of Rural Households in Mexico, IFPRI Research Report 139, Washington DC: International Food Policy Research Institute

Székely, Miguel; Lustig, Nora; Cumpa, Martin and Antonio Mejía, José (2000) Do We Know How Much Poverty There Is?, Inter-American Development Bank Working Paper 437, Washington DC: Inter-American Development Bank van Doorslaer, Eddy, et al. (2005) Paying Out-ofpocket for Healthcare in Asia: Catastrophic and Poverty Impact, EQUITAP Project Working Paper 2, Erasmus University, Rotterdam Wade, Robert Hunter (2004) 'Is Globalization Reducing Poverty and Inequality?', World Development 32.4: 567-89

World Bank (2003) World Development Report 2004: Making Services Work for Poor People, Washington DC: World Bank

Wuyts, Marc (2002) 'Aid, the Employment Relation and the Deserving Poor', in V. FitzGerald (ed.), Social Institutions and Economic Development. A Tribute to Kurt Martin, Dordrecht: Kluwer Academic Publishers: 169-87 